\title{
ARTIFICIAL NOURISHMENT AND SAND BY-PASSING IN THE AVEIRO INLET, PORTUGAL - NUMERICAL STUDIES
}

\author{
C. Coelho ${ }^{1}$, R. Silva ${ }^{2}$, F. Veloso-Gomes ${ }^{2}$, L. Rodrigues ${ }^{1}$
}

\begin{abstract}
Artificial sand nourishment systems are a potential solution to mitigate erosion beach problems, having been applied in many cases around the world, especially in the U.S.A. and Australia. For the Aveiro inlet, the artificial sand by-passing systems may be a good option, due to the availability of sediments accumulating at the north of the northern Aveiro inlet breakwater. A fixed artificial sand by-passing system can be proposed. However, fixed and continuous sand by-passing systems are the most expensive solutions. In order to reduce the economical aspect, periodic sand nourishment and semi-mobile systems are presented as an alternative. For those, different options of artificial nourishment can be proposed, depending on sediments volumes, location, distribution area, number of periodic operations, etc. Discussion about the results of the numerical simulations of shoreline evolution after different artificial nourishments scenarios at the southern part of the Aveiro inlet, in Portugal, is presented. Shoreline accretion/erosion rates, sediment transport volumes and profile sediment budgets have similar behaviors over time and along the coastal stretch, for all the tested scenarios. Generally, important coastal erosion can be mitigated with artificial nourishments and numerical modeling can help to improve the nourishments performance. For this open sandy coast, the sand nourishment simulations show better results near the deposit location for a period of time lower than 20 years. After that period, the nourishment effect is smaller. The southern profiles start benefiting with the nourishment after ten or more years.
\end{abstract}

Keywords: coastal erosion; artificial nourishment; sand by-passing; shoreline evolution; Aveiro inlet

\section{INTRODUCTION}

In a context of important coastal erosion, it is crucial to have tools available to decision-makers, which allow the evaluation of different scenarios, and the selection of the best engineering solutions to a particular coastal problem. Artificial sand nourishment systems represent a potential solution to mitigate the beach erosion problems. Innumerous successful cases were applied around the world, mainly in U.S.A and Australia. For the Aveiro inlet, located in the Portuguese northwest coast, the artificial sand by-passing system may be a good option, due to the availability of sediments accumulating at the north of the northern Aveiro inlet breakwater. A fixed artificial sand by-passing system can be proposed, as presented by Pinheiro (2006). That proposal was supported on the use of 5 semi-mobile pumps placed in the northern breakwater, in order to allow a greater coverage and a higher productivity. However, according to Pinheiro (2006), fixed and continuous sand by-passing systems are the most expensive solutions. In order to reduce the economical aspect, periodic sand nourishment and semi-mobile systems are also presented as an alternative to fixed systems.

The study of the several options of artificial sand by-passing is required for the Aveiro inlet, since this kind of system has never been used in Portugal and the area presents high erosion rates. The LTC numerical model (Coelho et al., 2004) was used to assess different sand nourishment solutions, in accordance with several scenarios, in order to try to understand their effects in the Aveiro inlet neighborhood. To do that, it was necessary to know some characteristics of the area, such as wave climate (wave height, wave direction and wave period), sediment grain size, sediment transport volumes, bathymetry and topography. The studied solutions included the two types of sand by-passing systems: continuous sand nourishment (sand by-pass) and periodic sand nourishments (artificial nourishment). The sediments source area was at the north of the northern breakwater of the Aveiro inlet (at S. Jacinto).

In the numerical simulations performed with the LTC model, a constant wave, representative of the wave climate was adopted, in order to allow an easier comparison of results. Firstly, a non-intervention situation corresponding to no sediments nourishment down drift of the Aveiro inlet was considered. Then, sand by-passing nourishment was assessed, representing different sediment transport rates crossing the Aveiro inlet. Different situations of sand nourishments were also tested, assuming that sources and sinks correspond to areas where the sediments are removed or distributed in a uniform way. The dredging area was maintained for all tests. Deposition conditions differed in added volumes, location in depth, location along the coast, deposition area and time and number of works operations.

\footnotetext{
${ }_{2}^{1}$ Civil Engineering Department, Aveiro University, Campus Universitário de Santiago, 3810-193 Aveiro, Portugal

2 Hydraulics and Water Resources Institute, Faculty of Engineering - University of Porto, Rua Dr. Roberto Frias, 4200-465, Portugal
} 
For each of the simulations, solid transport volumes, sediment budgets in control sections and shoreline advance or retreat rates were compared and analyzed.

\section{ARTIFICIAL NOURISHMENT AND SAND BY-PASSING SYSTEMS}

The artificial sand nourishment consists on dredging sediments, to be transported and deposited in an area where they are in deficit (Figure 1). Sand by-passing systems are one type of artificial sand nourishment processes, which can be used for mitigating the negative erosive effects introduced by the construction of breakwaters, trying to reproduce the previous natural movement of sediments.

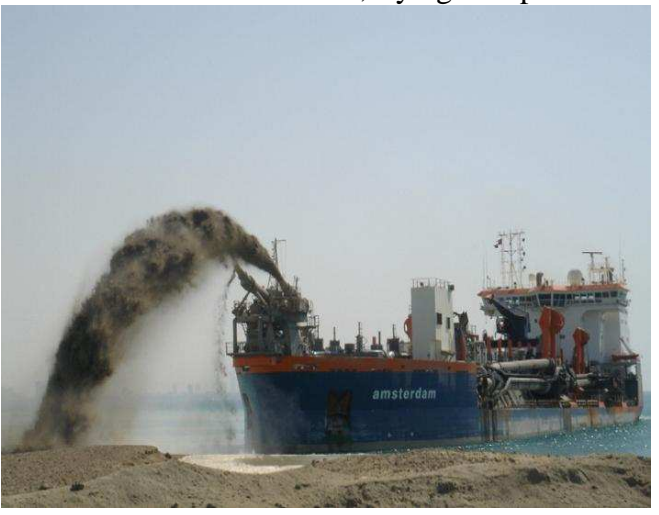

a) Hydraulic dredging system

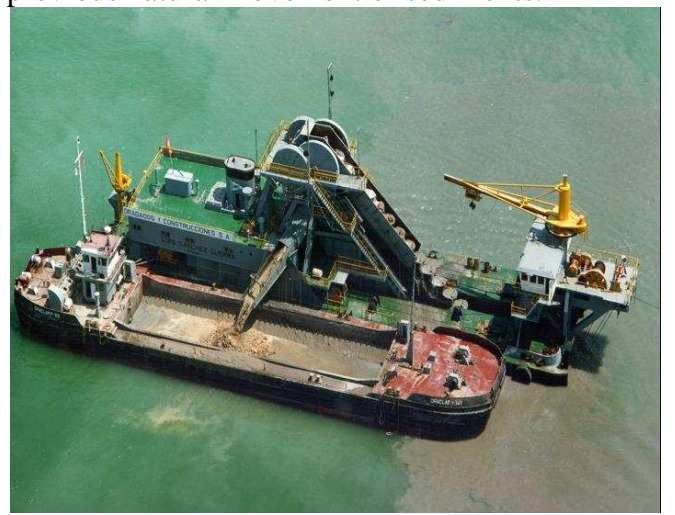

b) Mechanical dredging system

\section{Figure 1. Aspects of dredging operations}

Some aspects should be considered in order to guarantee a good design of sand nourishment interventions. For instance, it is important to define the characteristics of the sediments used in the nourishment intervention. Sediments grain size should be similar to the characteristic of the nourished beach, because coarser sand, in spite of being more stable would define higher slopes than the original beach and finer sand would be easily transported by the typical waves. Sediments color, mineral composition and specific weight are attributes which will affect beach users' patterns. For instance, a different color of the sand could reduce the number of beach users. Sediments toxicity can forbid their use. In fact, many of the dredged sediments are polluted and cannot be used. OSPAR Convention defines rules for the use of sediments (OSPAR, 2008). Of course, sediments availability is fundamental and the distance between the nourishment source and the deposition area should be considered on the nourishment design. A good sustainability of operations corresponds to artificial nourishment with sand from dredged inlets, which have a low contamination degree and grain sizes compatible with the contiguous beaches.

For a beach nourishment intervention it is required the knowledge of the local topography and bathymetry and the available amounts of sediments. Dredging and monitoring plans must be defined. It is also important to compare the case study with previous experiences. Three different types of nourishment effects should be evaluated: bottom level rise; turbidity, noise and perturbation of the local community associated to the nourishment operations; distribution of the added material along the coast over time. The last factor is analyzed in this paper.

\section{STUDY AREA}

The Aveiro inlet is located in the northwest Portuguese coast (Figure 2), which is a highly energetic sandy coast, with a typical wave regime from northwest, characterized by a mean significant wave height of $2 \mathrm{~m}$ and a mean wave period of $12 \mathrm{~s}$. During storms, occurring especially in the winter, offshore significant wave heights may reach $8 \mathrm{~m}$ and persist up to 5 days (Costa et al., 2001). The tide regime is semi-diurnal with a tidal range between $2 \mathrm{~m}$ and $4 \mathrm{~m}$ in spring tides. The potential alongshore transport is mainly due to the wave action with values between 1 and $2 \times 10^{6} \mathrm{~m}^{3} /$ year. Along this coastal stretch, the natural processes of sediment transport have been changed by the construction of breakwaters, needed to ensure good conditions in navigation channels, at harbors entrances and inlets. Consequently, accretion beaches develop on the up drift side of the breakwaters and shorelines' retreat down drift, with potential negative effects on local economy and tourism (Silva et al., 2007). 


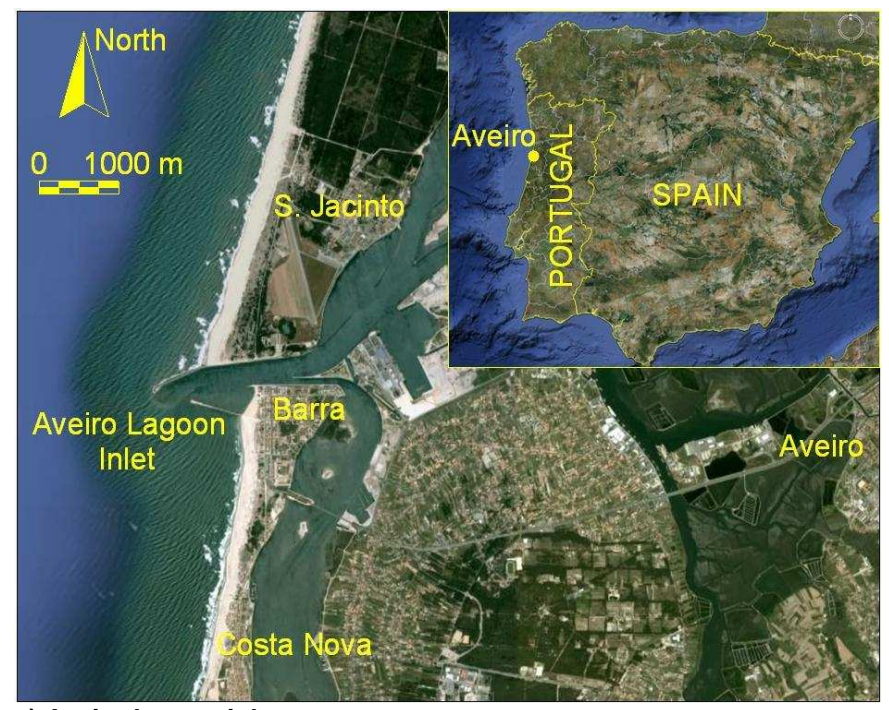

a) Aveiro lagoon inlet

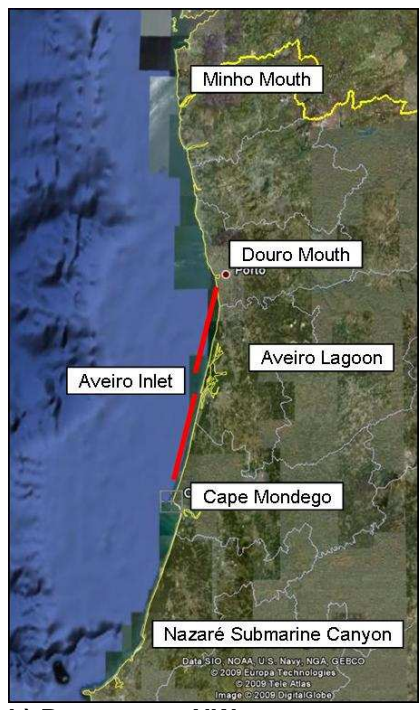

b) Portuguese NW coast

\section{Figure 2. Location of the study area (Google Earth)}

The coastal erosion causes and their relative importance are site specific, changing from place to place. In the Portuguese northwest coast case, namely between Douro river and Nazaré, coastal erosion is mainly due to the generalized sea-level rise, the misruled littoral occupation and use, sometimes with natural defenses destruction, the external works in harbors which result in perturbations in the littoral system and the reduction of sediments supply from natural sources. Moreover, the sediment supply reduction (negative sediment transport balance is mainly due to the decrease of Douro river sediment supply) is considered the main cause of the erosion problem felt in this coastal stretch (Silva et al., 2007).

Douro river sediment transport reduction is related to Human actions. The sediments supply to coastal areas decreased drastically in the last 30 years. Pointed values for natural conditions are from 1.5 to 2 million $\mathrm{m}^{3} /$ year of sediment supply by Douro river, but now that value is under $250000 \mathrm{~m}^{3} /$ year (Bettencourt, 1997). Anthropogenic actions in the Douro river basin that interact with the sediment transport rates can be of two different types: works on the river itself or in its basin. Those actions represent variations on available water and sediment volumes and sediment transport capacity. The works on the river have impact on the sediment volumes in transport and interventions on the basin have impact on the production of sediments by soil erosion. Dams for hydroelectric purposes, for water supply, for irrigation and for leisure activities, dredging to allow navigability, sand extraction for construction and fluvial protection works can be referred as the first type. Changes in the land use, on the agricultural techniques and on the soil protection are included in the second type of anthropogenic actions (Coelho et al., 2009).

\section{METHOD}

\section{Numerical Model}

If the important coastal erosion problems are due to the reduced amount of sand, to feed the coastal stretch with sediments can be a solution to mitigate the problem. With the goal of study shoreline evolution and coastal defense interventions, a numerical model (LTC - Long Term Configuration) for coastal evolution simulation at medium to long term was developed. It was firstly presented in ICCE 2004 (Coelho et al., 2004) and has been improved (Coelho et al., 2007). The model combines a classical one-line model with a rule based model. It was designed for sandy beaches where the main cause of shoreline evolution is the alongshore sediment transport, essentially dependent on the wave regime, the sediment characteristics and the sand availability. The model assumes that each wave acts during a certain period of time (computational time step) and is able to generate sediment transport. The model requires three-dimensional topographic data which is changed during calculation. Moreover, different coastal structures can be simultaneously considered and extensive areas can be represented up to fifty years. 
The volume of sediments in transport alongshore is given through the continuity equation and it is distributed along the active profile, according to predetermined rules, between the closure depth and wave run-up limit. The alongshore transport rates are estimated through the application of formulae which depend on the shoreline to wave breaking angle and the wave breaking height and, in some cases, on the beach slope and on the sediment grain size. The wave transformation by refraction, diffraction and shoaling is modeled in a simplified manner, or, wave conditions may be imported from more complex wave models. The shoreline's changes are due to gradients of the alongshore transport rates between adjacent beach cells, just like in the case of a classical one-line model (Figure 3).

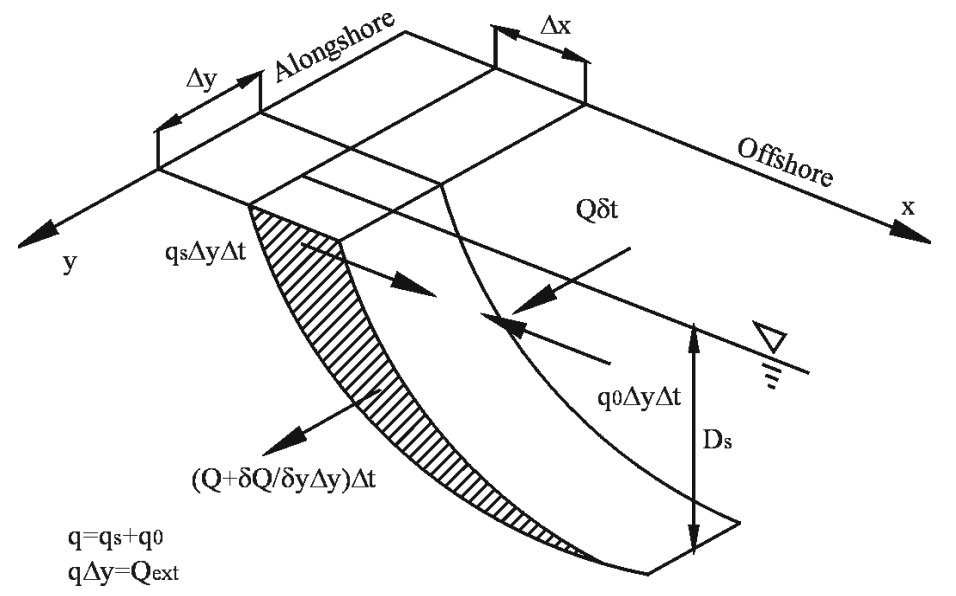

Figure 3. One-line model definition scheme (adapted from Horikawa and Isobe, 2005)

The balance of the volumes of sand is done through the continuity equation, Eq.1.

$$
\frac{\partial V}{\partial y}=\left(\frac{\partial Q}{\partial y}-q\right) d t
$$

The variation of the volume of sand, $V$, along an infinitesimal length of the shoreline is the same as the variation of the alongshore transport rates, $Q$, in that length added or subtracted of eventual external sediments, Eq.2.

$$
\Delta V=\left(\Delta Q-Q_{\text {ext }}\right) \Delta t
$$

The variation of the volume of sand in an infinitesimal length along the beach represents a variation in the depth level of the points in the same profile. Erosion/accretion is distributed along the active cross-shore profile, between the closure depth and wave run-up limit (Figure 4). Near the closure depth, in an accretion situation, the angle of repose, $\phi$, controls the sediment distribution and in an erosion situation, the control is made by the minimum underwater bottom slope. Near the wave run-up limit, the controlling parameters are the angle of repose and minimum beach face slope, respectively for erosion and accretion. An important improvement is achieved through this model: different profile evolution slopes may be tested under different erosion or accretion situations, reducing the limitations of not knowing the profile shape evolution over time (Coelho et al., 2007).

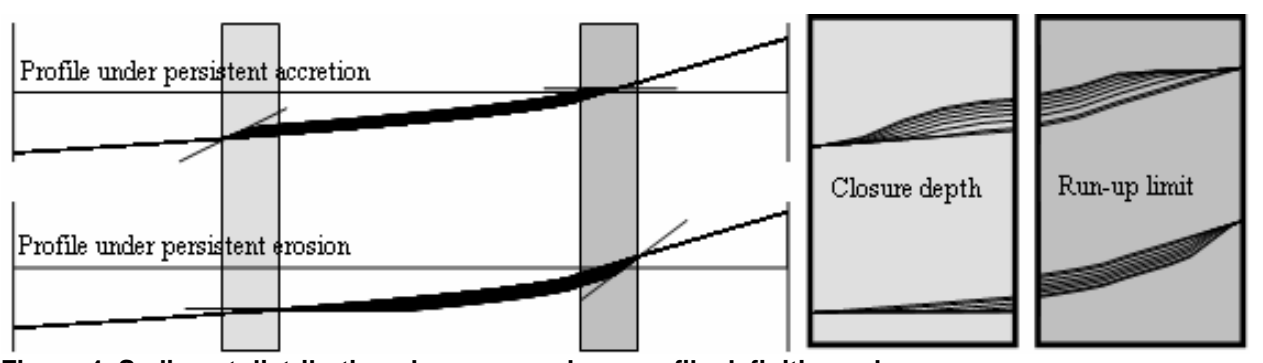

Figure 4. Sediment distribution along cross-shore profile definition scheme. 
Due to the importance of the boundary conditions in the model simulations, several options can be made: constant sediment volumes going in or out; constant volume variations in the border sections; extrapolation from nearby conditions. Moreover, different coastal protection works combinations may be considered with almost no limitation for the number of groins, breakwaters and seawalls, the number of sediment sources/sinks sites or artificial nourishments (Silva et al., 2007).

The artificial nourishment model simulation adopts a uniform distribution of the sediments in the defined area and then distributes it, according to stability parameters of the sand. After the nourishment, the sand is moved from the sink location due to wave action. Figure 5 represents an example of the simulation of the energetic wave action over the nourishment area, for a constant wave representing wave climate.

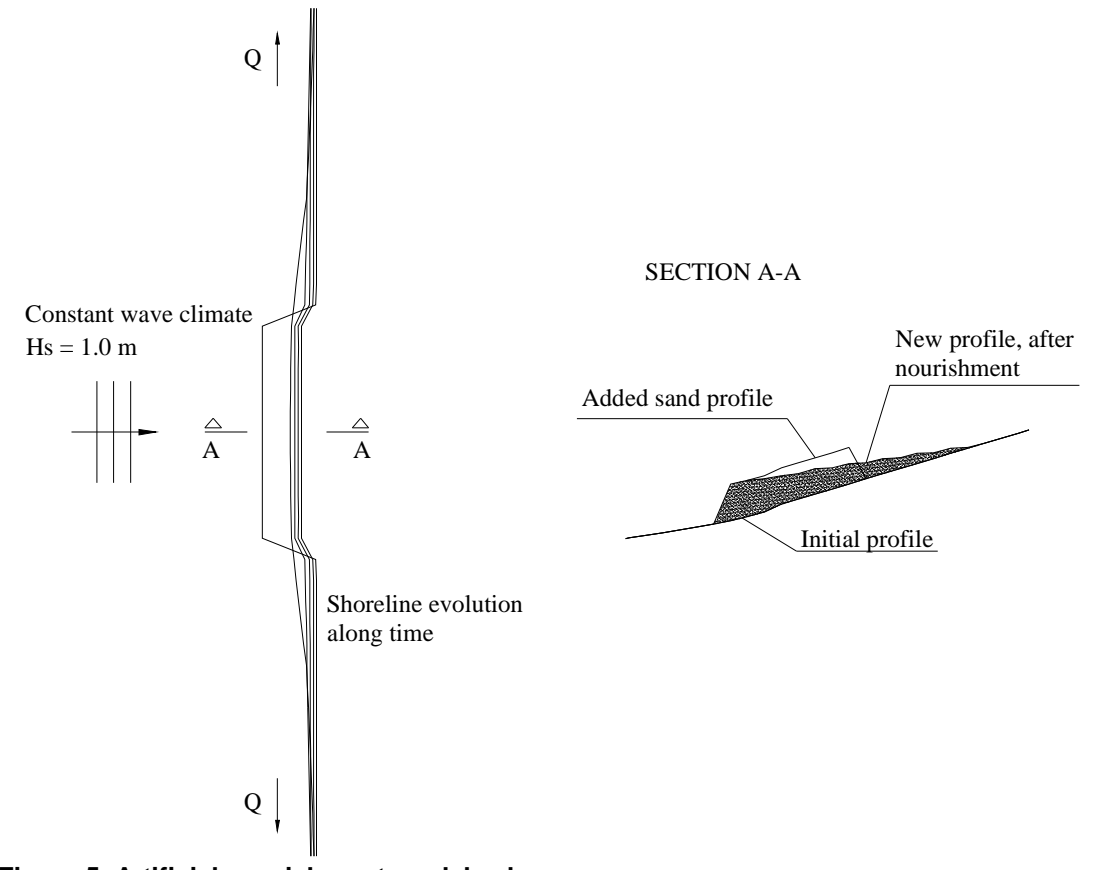

Figure 5. Artificial nourishment model scheme.

The LTC numerical model was used to assess different sand nourishment solutions, in accordance with several scenarios, in order to try to understand their effects in the Aveiro inlet neighborhood. The sediments source area was located at north of the northern breakwater of the Aveiro Lagoon inlet (at S. Jacinto, Figure 2). The LTC numerical model was used to perform the discussion of the relative importance of the several design options on the nourishment intervention.

\section{Reference Situation}

Due to model difficulties and uncertainties, a reference situation was defined, allowing comparison of the results and a qualitative analysis of the nourishments behaviour. The reference situation was defined according to indicative sediment transport volumes along the Portuguese northwest coast, shoreline erosion rates and sediment balances. During the calibration process nourishment was not considered and the sediment volumes in transport were just depending on the wave climate, the grid borders definitions at north and south frontier of the study area, coastal defense structures (Figure 6) and parameters (closure depth, wave run-up, sediment transport formula, etc.).

In the numerical simulations, a constant wave was adopted, to allow an easier comparison of the results. The wave height was $1.5 \mathrm{~m}$ and the wave direction angle was 65 degrees rotated from the north. All the modelling results were analysed along time in control profiles, $6500 \mathrm{~m}$ distanced from each other. The adopted profiles represent situations located immediately up drift and down drift from coastal defense structures, as well as areas far from the coastal defense structures influence (Figure 6). The results were checked for 1, 2, 5, 10, 20 and 50 years of simulation. For the reference situation, without nourishment, the application of the CERC (1984) formula, with a calibration coefficient (K) of 0.05 showed results consistent with the observed in the real area.

As referred, sediment transport volumes, shoreline erosion rates and sediment balances in the profiles were controlled. All the results were analyzed at the control profiles (Table 1). 


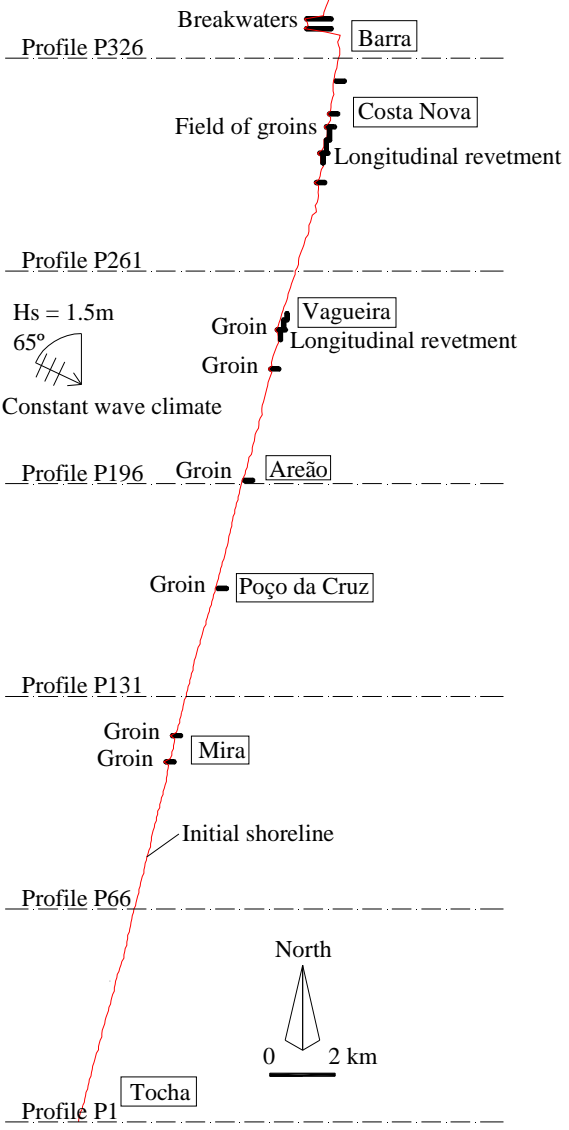

Figure 6. Modeling characteristics of the studied area (wave climate and coastal defense structures).

\begin{tabular}{|c|c|c|c|c|c|c|c|}
\hline \multirow{2}{*}{ Parameter } & \multirow{2}{*}{$\begin{array}{l}\text { Years of } \\
\text { simulation }\end{array}$} & \multicolumn{6}{|c|}{ Control Profiles } \\
\hline & & P326 & P261 & P196 & $\mathrm{P} 131$ & P66 & $\mathrm{P} 1$ \\
\hline \multirow{6}{*}{$\begin{array}{l}\text { Shoreline } \\
\text { position } \\
\text { advance }(\mathrm{m}) \\
\text { "-" represent } \\
\text { shoreline } \\
\text { retreat }\end{array}$} & 1 & 9.0 & 5.7 & -25.0 & 15.4 & -11.9 & 6.0 \\
\hline & 2 & -5.4 & 6.3 & -27.9 & 22.8 & -12.8 & 6.0 \\
\hline & 5 & -95.0 & 7.2 & -34.9 & 51.4 & -12.1 & 6.0 \\
\hline & 10 & -217.1 & 8.8 & -47.1 & 64.8 & -12.3 & 6.1 \\
\hline & 20 & -241.3 & 9.0 & -82.5 & 75.0 & -15.8 & 6.0 \\
\hline & 50 & -246.3 & -229.6 & -151.9 & 81.8 & -43.6 & 6.0 \\
\hline \multirow{6}{*}{$\begin{array}{c}\text { Accumulated } \\
\text { sediment } \\
\text { transport } \\
\text { volumes } \\
\text { crossing } \\
\text { profile } \\
\left(\times 10^{6} \mathrm{~m}^{3}\right) \\
\end{array}$} & 1 & 0.3 & 0.2 & 0.2 & 0.2 & 0.2 & 0.2 \\
\hline & 2 & 0.6 & 0.3 & 0.4 & 0.4 & 0.5 & 0.4 \\
\hline & 5 & 1.1 & 0.8 & 1.0 & 0.8 & 1.2 & 1.0 \\
\hline & 10 & 1.4 & 1.5 & 1.9 & 1.6 & 2.3 & 2.1 \\
\hline & 20 & 1.6 & 3.1 & 3.8 & 3.3 & 4.3 & 4.1 \\
\hline & 50 & 1.8 & 6.0 & 8.9 & 8.5 & 10.3 & 10.4 \\
\hline \multirow{6}{*}{$\begin{array}{l}\text { Sediment } \\
\text { balances } \\
\left(\mathrm{m}^{3} / \mathrm{m}\right) \\
\text { “-“ represent } \\
\text { volume } \\
\text { reduction in } \\
\text { the profile }\end{array}$} & 1 & 139 & 61 & $\begin{array}{l}-170 \\
\end{array}$ & 151 & -89 & 48 \\
\hline & 2 & -72 & 70 & -190 & 234 & -96 & 48 \\
\hline & 5 & -628 & 81 & -236 & 364 & -92 & 48 \\
\hline & 10 & -1079 & 101 & -314 & 424 & -94 & 45 \\
\hline & 20 & -1224 & 105 & -446 & 481 & -116 & 45 \\
\hline & 50 & -1259 & -694 & -764 & 518 & -527 & 46 \\
\hline
\end{tabular}

Results lead to shoreline retreat in profiles P326 and P196. Those profiles are located immediately down drift of groins or breakwaters. Profiles P261 and P131 are in stable or accretion situation, corresponding to areas protected down drift by coastal structures (Figure 6). However, important erosion is felt in profile P261 in the last years of the simulation, due to equilibrium reached at north and consequent reduction of sediment transport to south. This effect also occurs at profile P66. 
Sediment transport volumes develop to stable values, mainly evident at profile P326, where the last 30 years of simulation just represent 0.2 million of cubic meters of sediments moving across the profile. The sediment balance in each profile is related with the shoreline behavior at each profile and thus, negative sediment budgets represent shoreline retreats.

\section{Tested Scenarios}

Different situations of sand nourishments were tested, assuming that sources and sinks correspond to areas where the sediments are removed or distributed in a uniform way. The dredging area was maintained for all the tests, while deposition conditions differed in added volumes, location in depth, location along the coast, deposition area and time and number of works operations. A sand by-passing situation was also tested, for different sediment sink in the southern beaches and different sediment transport rates crossing the Aveiro inlet. For each of the simulations, volumes of solid transport, sediment budgets in control sections and shoreline advance or retreat rates were compared and analyzed. Due to the consistent behavior of the monitored parameters (shoreline position, sediment transport volumes and sediment profile balances), in the following analysis only the shoreline position variation is presented.

The knowledge of nourishment behavior is important to improve intervention efficiency. Thus, the location, the time of the nourishment operations and the volumes applied were tested in order to obtain the best results in the future potential works. Firstly, it was defined a deposition area of $300 \times 500 \mathrm{~m}^{2}$, located between about $500 \mathrm{~m}$ and $200 \mathrm{~m}$ from the shoreline. For this area, different nourishment volumes were tested during a single nourishment process of two months of continuous work, starting at the beginning of the simulation. After this, a different number of deposit operations and different times to perform the works were tested, maintaining the nourishment volume $\left(1 \times 10^{6} \mathrm{~m}^{3} / \mathrm{year}\right)$ and area $(300 \mathrm{x}$ $500 \mathrm{~m}^{2}$ ). A similar simulation was performed to compare sand nourishment system and sand by-passing system, with continuous sediments feeding, corresponding to $1 \times 10^{6} \mathrm{~m}^{3}$ at the end of the 50 years of simulation. After the referred tests, variations in the nourishment area (longitudinal and transversal variations), dimension and location were analyzed, maintaining always the same volumes of nourishment, corresponding to $1 \times 10^{6} \mathrm{~m}^{3} /$ year, deposited during two months starting right at the beginning of the modeling simulation (Figure 7).

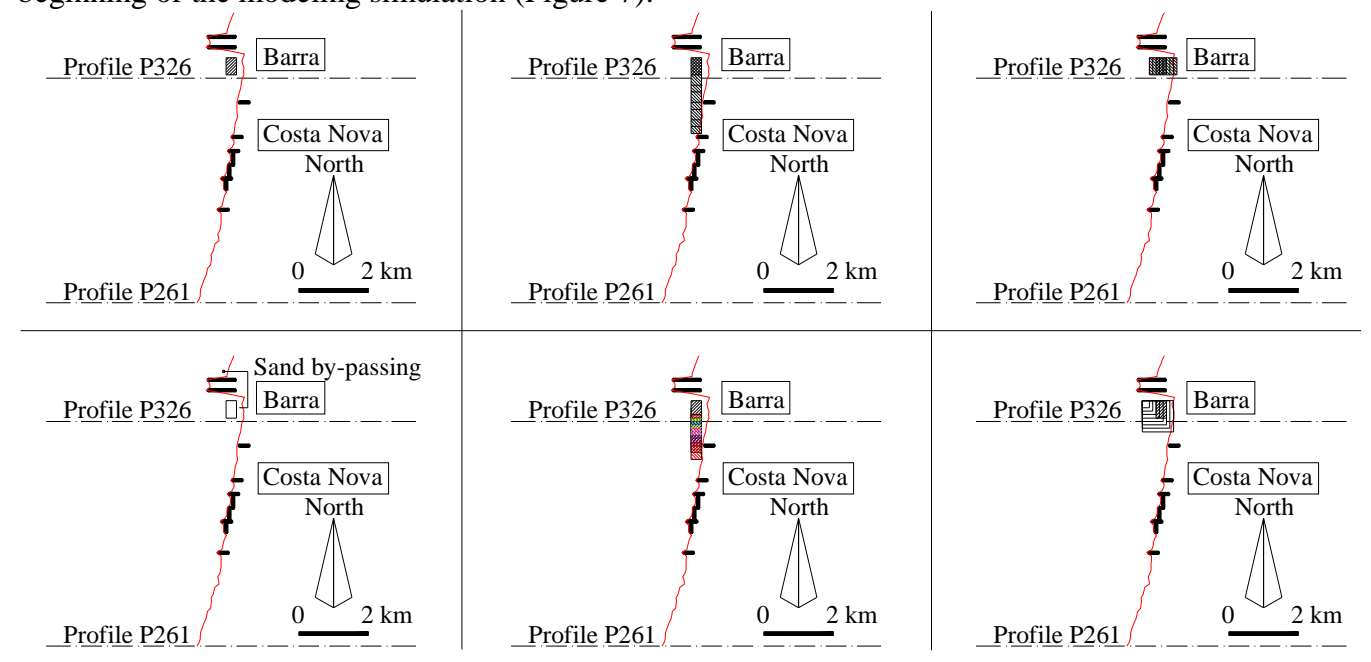

Figure 7. Tested scenarios (from left to right and top to bottom: added volumes and time and number of nourishment operations, nourishment area longitudinal extension, nourishment area transversal extension, sand by-passing, nourishment area location and nourishment area dimension).

Generally, the nourishment area is located northern from profile P326. The variations on deposition area were always performed maintaining the limits of the deposit inside the active profile, between the closure depth and the run-up limit.

\section{RESULTS}

The nourishment interventions represent a better shoreline behavior, reducing the shoreline retreat levels of the reference situation. For all the tests it is noticed an important quick effect (that decreases in time) on profile P326 and latter effects are visible further south. In fact, with time, sediment 
nourishment effects are almost zero on profile P326, being moved to profiles P261 and P196. For the profiles located southern from P196, the impact of the nourishment is almost null, as visible in Figure 8d. Thus, profiles P66 and P1 are not represented in the next figures and are not described in the analysis.

\section{Variation on added volumes}

Eight different nourishment volumes were tested, starting in $0.25 \times 10^{6} \mathrm{~m}^{3}$ of sediments and increasing $0.25 \times 10^{6} \mathrm{~m}^{3}$ in each test. To add a volume of $0.25 \times 10^{6} \mathrm{~m}^{3}$ has significantly less impact then to add greater amounts of sand. The other volumes have similar impacts, mainly in the southern profiles. As it is possible to observe in Figure 8a, near the nourishment area, the effect of the sand added is higher in the first ten years and dependent on the volume introduced in the coastal system. In Figure $8 \mathrm{~b}$ the effect of the nourishment is lower and starts mainly 20 years after the nourishment. For this local, the volume of sand introduced is not so important, since it is dispersed along the coastal stretch, being homogenized by coastal erosion and deposition occurring over areas up drift profile P261.

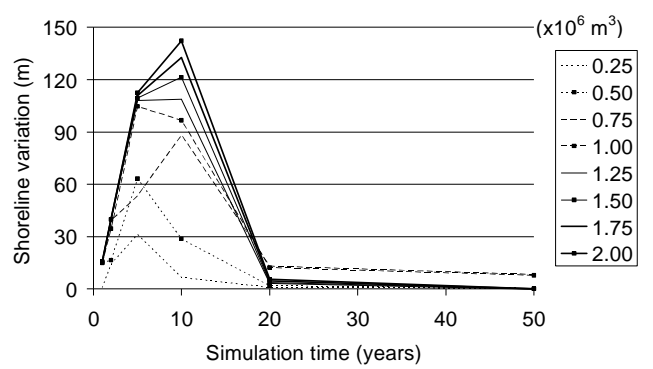

a) Profile P326

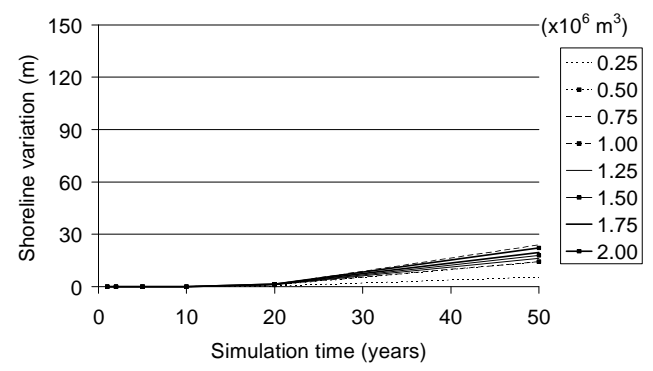

c) Profile P196

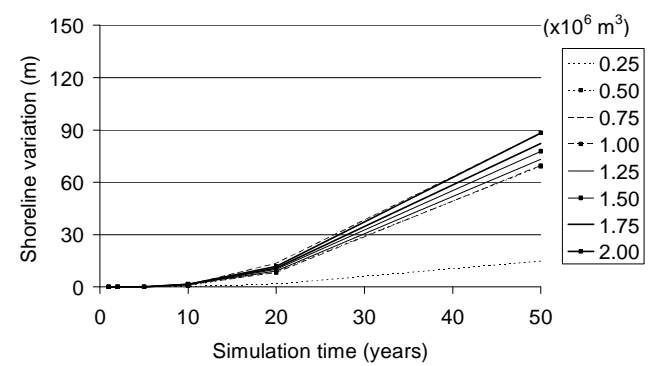

b) Profile P261

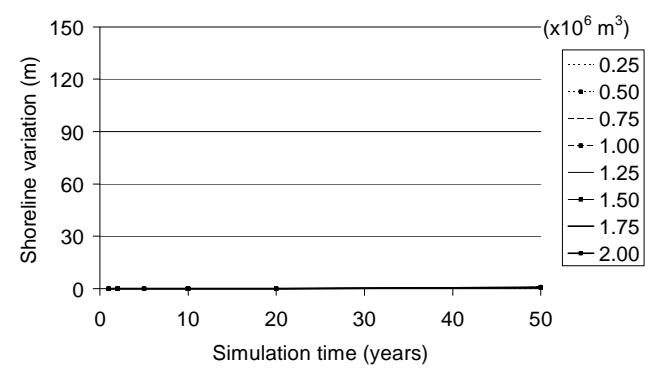

d) Profile P131

Figure 8. Shoreline variation, compared with reference situation, for different nourishment volumes.

\section{Variation on time of nourishment operations}

Figure 9 shows the effect of the duration of the nourishment operations ranging from one month to one year, applying one million cubic meters of sand.

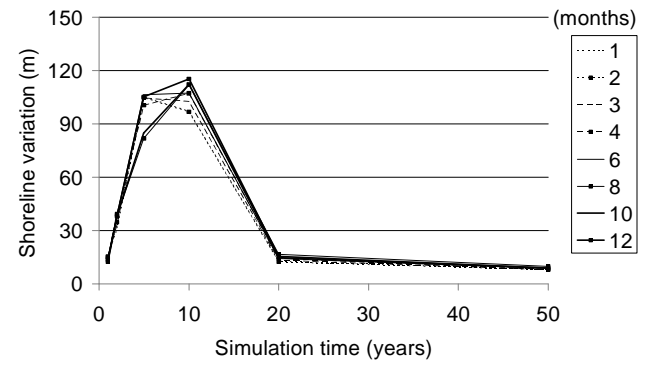

a) Profile P326

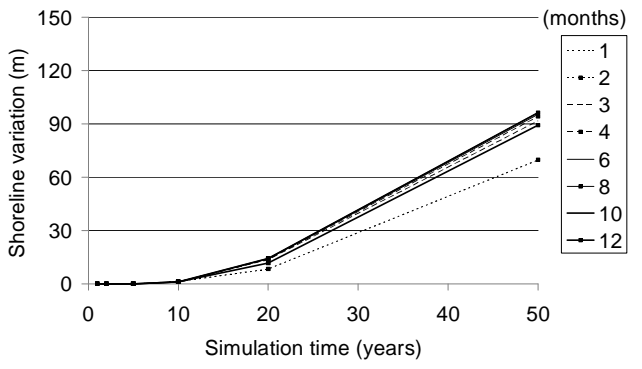

b) Profile P261

Figure 9. Shoreline variation, compared with reference situation, for different durations of the nourishment operations.

This deposit of sand in an area of $300 \times 500 \mathrm{~m}^{2}$ represents different layer thickness of added sediments, which decrease with longer times of nourishment processes. To perform the nourishment 
over shorter or longer periods of time seems to represent small differences in the nourishment results. Effects in southern profiles are even less representative.

Variation on longitudinal extension of the nourishment area

Sand deposit in different areas extension represents again variation on sand layer thickness, but also causes direct impact on different extension of the coastal stretch. Generally, greater extensions of sediment deposit areas reduce the local effect of the nourishment. Another important consequence is that sand deposit located down drift the profile P326 can represent negative effects on it, because refraction can change the sediments transport direction. An area of $300 \times 800 \mathrm{~m}^{2}$ corresponds to deposition of sand directly on profile P326, but inversion of wave direction due to refraction is observed for nourishment areas of more than $1300 \mathrm{~m}$ of longitudinal extension, when the major amount of sediments is sink down drift profile P326 (Figure 10).

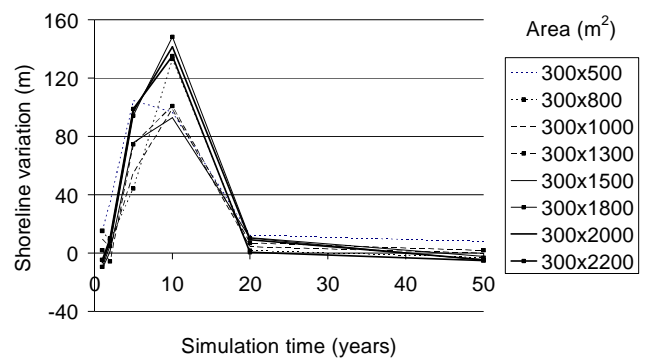

a) Profile $P 326$

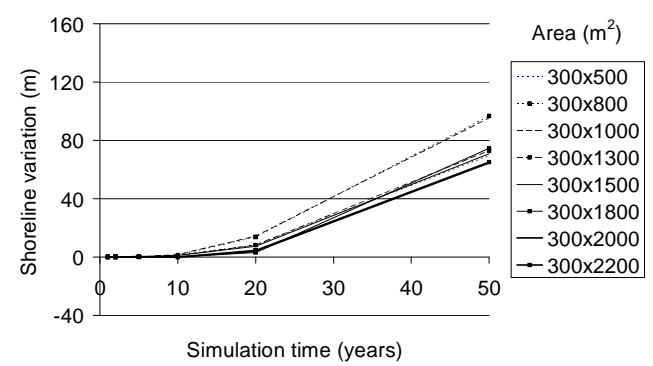

b) Profile P261

Figure 10. Shoreline variation, compared with reference situation, for different longitudinal extensions of the nourishment area.

Down drift profile P261, the shoreline behavior is similar to the observed at profile P261, but with much less significance, as showed in Figures $8 \mathrm{~b}$ and $8 \mathrm{c}$ for the variation of added volumes.

Variation on transversal extension of the nourishment area

The variation of transversal extension of the nourishment areas from $100 \mathrm{~m}$ to $800 \mathrm{~m}$, increasing landward, was tested for an area located up drift profile P326, maintaining a longitudinal extension of $500 \mathrm{~m}$. The impacts of the nourishment have very similar effects for all of the adopted areas. Even thought, a better behavior for the smaller nourishment areas is observed in profile P326, mainly after 5 and 10 years (Figure 11a).

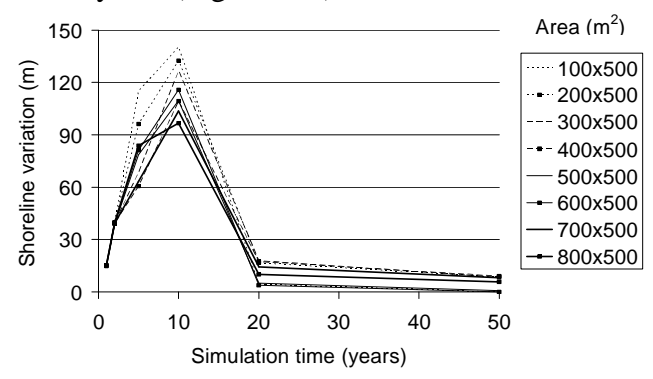

a) Profile P326

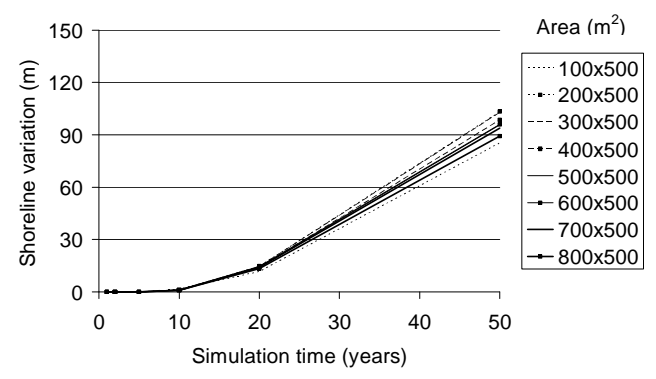

b) Profile P261

Figure 11. Shoreline variation, compared with reference situation, for different transversal extensions of the nourishment area.

\section{Variation on nourishment area location}

Maintaining the nourishment area of $300 \times 500 \mathrm{~m}^{2}$, eight locations were tested, named artificial nourishment AN1 to AN8, from north to south, respectively. Artificial nourishment AN2 and AN3, located over the analyzed profile P326, show direct impact on shoreline advance, representing immediately much better results than the other simulated tests (Figure 12a). However, this rapid effect decreases for a 5 years analysis. For instance, after two years of simulations for test AN3, sediments are mainly located southern from profile P326, leading to sediment transport to the north of profile P326 and to the south of the sediments deposit area, conducting to shoreline retreat at profile P326 (for two years of simulation, this profile behavior is comparable to a cape). 
The sand deposit just down drift profile P326 (AN4) represents erosion effects on it, again because refraction changes the sediments transport direction conducting to a local behavior similar to a cape. This cape erodes along time, representing a linear shoreline 5 years later, reversing the sediment transport direction again from north to south.

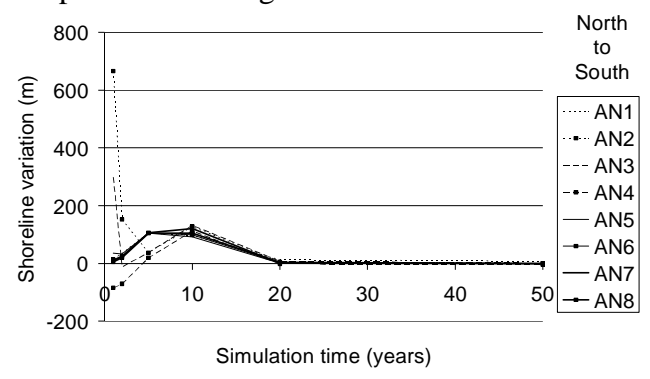

a) Profile P326

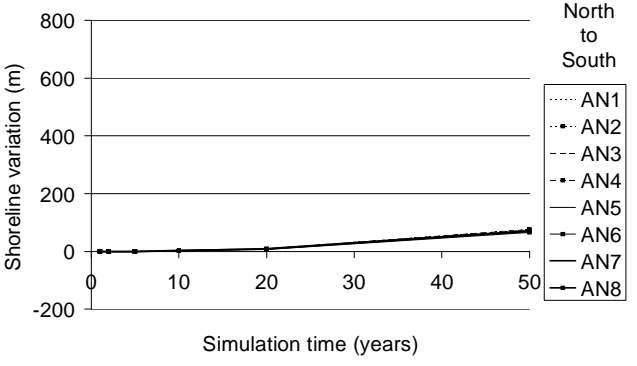

b) Profile P261

Figure 12. Shoreline variation, compared with reference situation, for different locations of the nourishment area.

As expected, southern locations of the deposit, being near the southern profiles, allow better performances in profile P261 than the previous tested scenarios.

\section{Variation on nourishment area dimension}

The main impact of the variations in the dimension of the nourishment area is on the sand layer thickness of the deposit. Figure 13 allows observing two groups of results. Smaller deposit areas, with higher thickness layers, represent better behaviors. Generally, for these different nourishment areas, the magnitude of the impacts is lower.

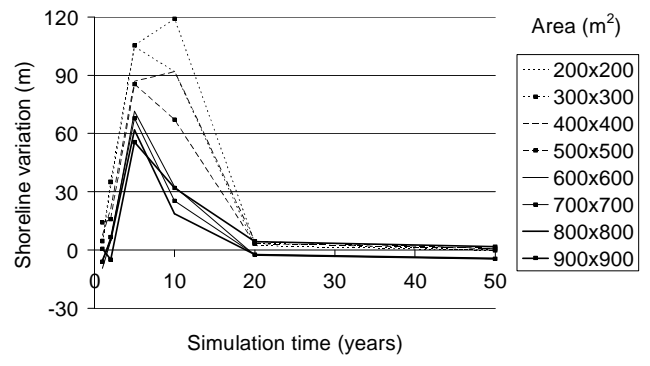

a) Profile P326

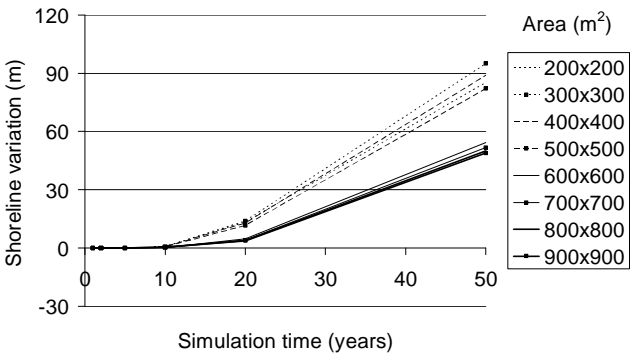

b) Profile P261

Figure 13. Shoreline variation, compared with reference situation, for different dimensions of the nourishment area.

Again, refraction inverts the sediment transport direction in profile P326, during the first year of simulation, for areas of $600 \times 600 \mathrm{~m}^{2}$ or larger, because sediments are sink down drift the control profile.

\section{Variation on number of nourishment operations}

To realize if it is better to perform the nourishment process in a single operation, or sink the sand in lower volumes, during more operations, the one million cubic meters of nourishment was split by ten and deposited every five years during two months. The profiles behavior was registered in time and was also compared with a sand by-passing system corresponding to a continuous nourishment of 2.3 $\mathrm{m}^{3}$ /hour, during the 50 years of simulation. Figure 14 shows the results.

To nourish the area with all the amount of sand in a single operation has naturally quicker and a higher effect on profile P326. According to sediment transport direction, this effect will move to south, also with higher positive impacts (visible in Figure 14b). However, near the location of the nourishment area, the first quick effect will decrease in time and thus, the lower by-passing amounts per hour represent better results near profile P326 at the end of the 50 years of simulation (Figure 14a). 


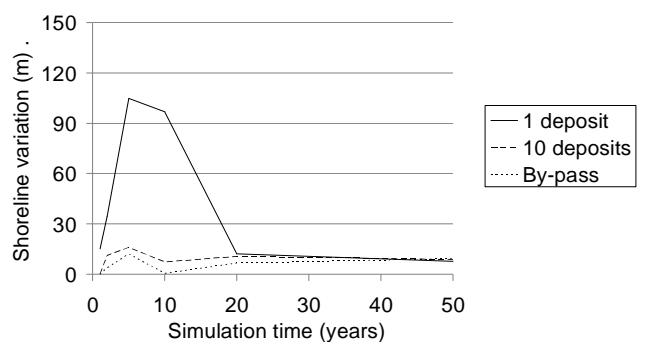

a) Profile P326

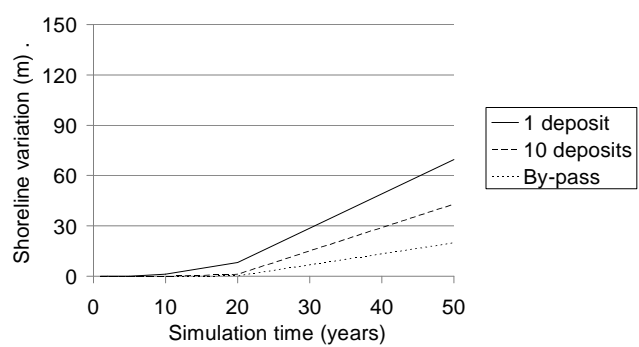

b) Profile P261

Figure 14. Shoreline variation, compared with reference situation, for different number of nourishment operations.

\section{CONCLUSIONS}

Artificial sand nourishment systems are a potential solution to mitigate beach erosion problems having been applied in many cases around the world, especially in the U.S.A. and Australia. For the Aveiro inlet, the artificial sand by-passing systems may be a good option, due to the availability of sediments accumulating at the north of the northern Aveiro inlet breakwater. A fixed artificial sand by-passing system can be proposed. However, fixed and continuous sand by-passing systems are the most expensive solutions. In order to reduce the economical aspect, periodic sand nourishment and semi-mobile systems are presented as an alternative.

The behavior of artificial sand nourishment interventions in beaches of open and energetic coasts need to be very well understood due to the amount of sediments required, corresponding to important financial costs. The social perception of the population for these processes is also important. Artificial nourishment processes are immediately evaluated by end-users, which easily criticize the obtained results depending on their own interest. In spite of that, it is clear that important coastal erosion can be mitigated with artificial nourishments and numerical simulations can help to improve the nourishment performances.

Different options of sand nourishment were assessed through numerical simulation of the shoreline evolution at the southern part of the Aveiro inlet, in Portugal. The options were related with the added volumes of sediments, the location of the nourishment, the distribution area and the number of periodic operations. The results were discussed based on the analysis of shoreline accretion/erosion rates, sediment transport volumes and profile sediment budgets. These parameters had similar behaviors over time and along the coastal stretch, for all the tested scenarios. Generally, sand nourishment results are better near the deposit location for a period of time lower than 20 years. After that period, the effect of the nourishment is smaller. The southern profiles are benefiting from the nourishment after ten or more years. Further analysis is needed, to understand some localized shoreline behaviors and the location and dimension of the achieved accretion areas.

It is evident that, for an open and energetic coastal stretch, it is essential to define the real objectives of the nourishment process. Location and duration time of the nourishment benefits require clear description, to allow the characterization of the best design according to the goals. Some composed interventions, involving other structures as groins or longitudinal revetments can also be studied, including artificial nourishments to try to minimize some eventual negative impacts on the down drift shoreline neighborhoods.

\section{REFERENCES}

Bettencourt, P., 1997. Notas Para Uma Estratégia de Gestão da Orla Costeira, Colectânea de Ideias Sobre a Zona Costeira de Portugal, pp. 265-283 (in Portuguese).

CERC (1984). Shore Protection Manual. Washington, DC: U.S. Army Corps of Engineers, Coastal Engineering and Research Center, U.S. Government Printing Office.

Coelho, C., Taveira-Pinto, F., Veloso-Gomes, F. and Pais-Barbosa, J. 2004. Coastal Evolution and Coastal Works in the Southern Part of Aveiro Lagoon Inlet, Portugal, Proceedings of the $29^{\text {th }}$ International Conference on Coastal Engineering, Lisbon, Portugal, Vol. 4, pp. 3914-3926. 
Coelho, C., Veloso-Gomes, F. and Silva, R. 2007. Shoreline Coastal Evolution Model: Two Portuguese Case Studies, Proceedings of the $30^{\text {th }}$ International Conference, San Diego, USA. Vol. 4, pp. 3430-3441.

Coelho, C., Conceição, T. and Ribeiro, B. 2009. Coastal Erosion Due to Anthropogenic Impacts on Sediment Transport in Douro River - Portugal, Proceedings of Coastal Dynamics, Impacts of Human Activities on Dynamic Coastal Processes, Tokyo, Japan, Paper 72, 15 p.

Costa, M., Silva, R. and Vitorino, J., 2001. Contribuição para o Estudo do Clima de Agitação Marítima na Costa Portuguesa. Proceedings of $2^{a s}$ Jornadas Portuguesas de Engenharia Costeira $e$ Portuária, Sines, Portugal, 17-19 Outubro, 20 p. PIANC (in Portuguese).

Horikawa, K. and Isobe, M. 2005. Dynamic behavior of coastal sediment. Proceedings of the Japan Academy (Japan), Series B, Vol. 81, No. 9, pp. 363-381.

OSPAR (2008). OSPAR Comission 2008: Assessment of the environmental impact of dredging for navigational purposes. Biodiversity Series, OSPAR.

Pinheiro, J. 2006. Transposição Artificial de Sedimentos em Embocaduras, Master thesis, Engineering Faculty of Oporto University, 150 p. (in Portuguese).

Silva, R., Coelho, C., Taveira-Pinto, F. and Veloso-Gomes, F. 2007. Dynamical Numerical Simulation of Medium Term Coastal Evolution of the West Coast of Portugal, $9^{\text {th }}$ International Coastal Symposium, Gold Coast, Queensland, Australia. Journal of Coastal Research, SI 50, pp 263-267. 